\title{
Utilization of kelp-derived carbon sources by kelp surface-associated bacteria
}

\author{
Mia M. Bengtsson ${ }^{1,2, *}$, Kjersti Sjøtun ${ }^{1}$, Julia E. Storesund ${ }^{1}$, Lise Øvreås ${ }^{1,2}$ \\ ${ }^{1}$ Department of Biology, and ${ }^{2}$ Centre for Geobiology, University of Bergen, Box 7803, 5020 Bergen, Norway
}

\begin{abstract}
The surfaces of kelp are covered with bacteria that may utilize kelp-produced carbon and thereby contribute significantly to the carbon flux in kelp forest ecosystems. There is scant knowledge about the identity of these bacteria and about which kelp-derived carbon sources they utilize. An enrichment approach, using kelp constituent carbon sources for bacterial cultivation, was used to identify bacterial populations associated with the kelp Laminaria hyperborea that degrade kelp components. In order to assess whether the cultured bacteria are significant under natural conditions, partial 16 rRNA gene sequences from the cultured bacteria were compared to sequences obtained from the indigenous bacterial communities inhabiting natural kelp surface biofilms. The results identify different members of the Roseobacter clade of Alphaproteobacteria in addition to members of Gammaproteobacteria that are involved in kelp constituent degradation. These bacteria are observed sporadically on natural kelp surfaces and may represent opportunistic bacteria important in degradation of dead kelp material. Many of the cultured bacteria appear to be generalists that are able to utilize different kelp carbon sources. This study is the first to link culturable kelpassociated bacteria with their occurrence and possible roles in the natural environment.
\end{abstract}

KEY WORDS: Seaweed $\cdot$ Brown algae $\cdot$ Heterotrophic bacteria $\cdot$ Enrichment cultivation $\cdot 16 \mathrm{~S}$ rRNA Alginate $\cdot$ Laminaran $\cdot$ Fucoidan

Resale or republication not permitted without written consent of the publisher

\section{INTRODUCTION}

The kelp Laminaria hyperborea forms extensive underwater forests along the Atlantic coasts of Europe with large abundances in Norway. These forests provide food, shelter or growth substrate for a great biodiversity of macroscopic organisms, such as invertebrates, fish and epiphytic seaweeds (Tokida 1960, Christie et al. 2003). Kelp forests also sustain an invisible, but even more diverse, world of microbes that are for example found growing on the surfaces of the kelp. These biofilms, consisting mainly of bacteria (M. M. Bengtsson unpubl. data), coat all surfaces of the kelp and may play vital roles in the kelp forest ecosystem. Some heterotrophic marine bacteria are known to have the ability to utilize complex polysaccharides, for example, alginate and fucoidan that are produced by kelp (Wong et al. 2000, Sakai et al. 2002, 2003). Kelpassociated bacteria with such abilities can serve as food for micrograzers and filter feeding animals in the kelp forest, and contribute to the nutritional value of kelp material for these consumers (Norderhaug et al. 2003). In these ways, bacteria play a key role in making kelp primary production available to higher levels in the food chain (Newell \& Field 1983, Norderhaug et al. 2003).

Several strains of bacteria that are capable of degrading different kelp substances have been isolated from marine environments and investigated (e.g. Chesters \& Bull 1963, Uchida 1995, Sakai et al. 2002, 2003, Descamps et al. 2006). In these studies, the individual strains and their physiology were the focus rather than the ecological importance of the bacteria on kelp surfaces or in kelp forest ecosystems. Other studies have adopted a more ecological perspective, by studying the seasonal (Laycock 1974), spatial (Koop et al. 1982, Davis et al. 1983) or successional (Hollohan et al. 1986) dynamics of bacteria that grow on kelp substances. In these studies, the bacteria involved were not identified with high taxonomical resolution and it was not possible to compare the cultured bacteria with indigenous bacterial communities on kelp due to the 
methodological limitations at the time when the studies were carried out. Consequently, there is little knowledge of which types of kelp-carbon utilizing bacteria are captured by cultivation efforts and of their significance in indigenous kelp-associated bacterial communities.

The bacterial communities inhabiting the surfaces of kelps have recently been investigated using cultureindependent, molecular tools based on 16S rRNA (Staufenberger et al. 2008, Bengtsson et al. 2010). On surfaces of Laminaria hyperborea, the most frequently detected lineages were Planctomycetes, Alphaproteobacteria, Verrucomicrobia, Bacteroidetes and Gammaproteobacteria (Bengtsson et al. 2010). However, the ecological roles of the different types of bacteria have not been investigated. For example, it is not known which of the bacteria are sustained by kelp-produced substances and which of these substances they utilize.

The aim of this study was to pinpoint and identify bacterial populations that utilize different kelp constituents in order to gain insight into the ecological roles of the bacteria that inhabit kelp surface biofilms. This was achieved by an enrichment-based approach, using kelp constituent substances as carbon sources for cultivation of bacteria derived from kelp surface biofilms. Comparisons of 16S rRNA gene sequences obtained from the cultured bacteria with sequences from the indigenous bacterial communities on kelp surfaces, were made to assess the ecological significance of the cultured bacterial lineages on kelp surfaces.

\section{MATERIALS AND METHODS}

Sampling and sample processing. Laminaria hyperborea was sampled in September 2008 at 1 site $\left(60^{\circ} 09.706^{\prime} \mathrm{N}, 5^{\circ} 02.371^{\prime} \mathrm{E}\right)$ close to Bergen, Norway. Six kelp individuals were sampled by dredging from a boat and were brought back to the laboratory for processing within a few hours. Three $5 \times 5 \mathrm{~cm}$ pieces were cut out from different places (evenly distributed) on the middle lamina of each kelp individual and were rinsed thoroughly in sterile (autoclaved and sterile filtered) seawater to remove loosely attached (non-biofilm) bacteria. Biofilm material was scraped off the surfaces of both sides of the kelp pieces using a sterile scalpel. The biofilm material from all 3 pieces from each kelp individual was pooled by suspending it in $10 \mathrm{ml}$ of sterile seawater. Thus, each suspension contained $150 \mathrm{~cm}^{2}$ of biofilm from the same kelp individual. The biofilm suspensions were mixed thoroughly by vortexing and were kept on ice for a few hours until inoculation of the culture media (described in the next section).

Three smaller $(0.5 \times 0.5 \mathrm{~cm})$ pieces were cut out from each kelp individual and used for enumeration of biofilm cells. They were fixed, stained with DAPI (4', 6diamidino-2-phenylindole) and photographed under a fluorescence microscope. Biofilm cells were counted as described in Bengtsson et al. (2010).

Cultivation media. Six different media were prepared for cultivation of kelp biofilm bacteria. Of these, 4 contained a minimal base medium supplemented with different kelp constituents as carbon sources, and 1 was a control containing the minimal base medium without a carbon source. A commercial marine broth (Difco Marine Broth 2216) medium with complex carbon sources, such as peptone and yeast extract, was included in the experiments. All media were solidified with agar (Bacto Agar, grade A). The minimal base medium consisted of $1.25 \mathrm{mM} \mathrm{NH}_{4} \mathrm{NO}_{3}$ and $1.8 \%$ agar in $90 \%$ natural seawater $(\mathrm{v} / \mathrm{v})$, as well as $0.5 \mathrm{mM} \mathrm{Na}_{2} \mathrm{HPO}_{4}$, trace elements (Whitman et al. 2006) and vitamins (Wolin et al. 1963) that were added after autoclaving. The chemical structures of the kelp constituent carbon sources that were used in this study are given in Fig. 1.

Alginate is an anionic polysaccharide (Fig. 1) that is a structural component of brown seaweed cell walls, and is also found intercellularly. It makes up approximately 15 to $35 \%$ of the dry weight of Laminaria hyperborea laminae (Haug \& Jensen 1954). Fucoidan is a sulphated polysaccharide (Fig. 1) that is produced in specialized secretory cells in L. hyperborea and secreted to the surface of the thallus via mucilage channels (Evans et al. 1973). The exact structure of $L$. hyperborea fucoidan has not been determined. Fucoidan appears to be a minor constituent of Laminaria kelps, making up less than $4 \%$ of the dry weight (Black 1954). Laminaran is a storage polysaccharide of the cells of $L$. hyperborea and other brown seaweeds; It constitutes up to $30 \%$ of the dry weight of L. hyperborea laminae, and concentrations are highest between August and February, as a result of storage of carbon fixed by photosynthesis during the summer (Haug \& Jensen 1954). D-mannitol is a relatively simple sugar alcohol (Fig. 1) that, like laminaran, is an intracellular storage compound; however, it may also be released from kelp cells into the surrounding seawater by exudation (Wada et al. 2007). D-mannitol constitutes up to $20 \%$ of the dry weight of $L$. hyperborea laminae, and concentrations are highest from July to September (Haug \& Jensen 1954).

The polymers alginate (Protanal HF, FMC Biopolymer), fucoidan and laminaran were extracted from Norwegian Laminaria hyperborea and provided by FMC Biopolymer while D-mannitol was obtained commercially (Pearlitol $160 \mathrm{C}$, Roquette). The kelp constituents were added to the minimal base medium at $1 \mathrm{~g} \mathrm{l}^{-1}$ medium before autoclaving. The marine broth was diluted according to the manufacturer's instructions. The media were poured onto petri dishes (90 $\mathrm{mm}$ diameter). 


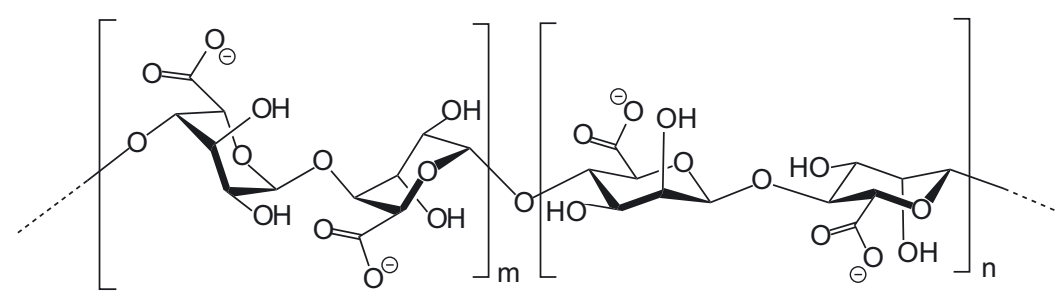

Fucoidan

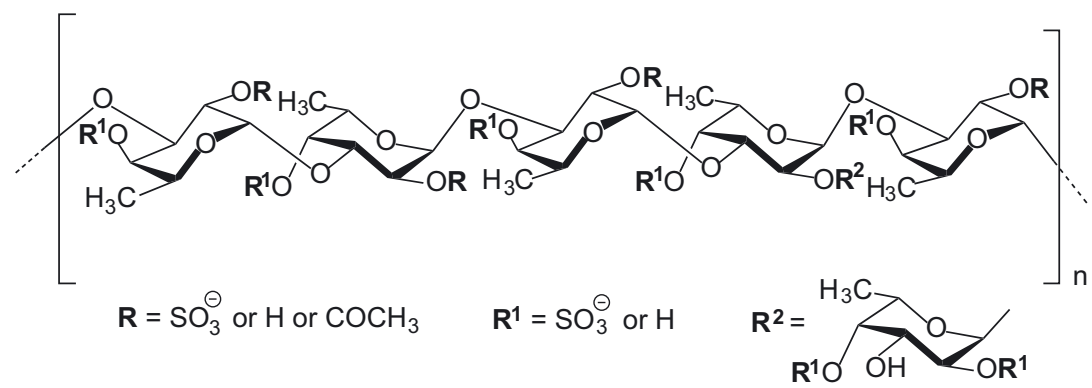

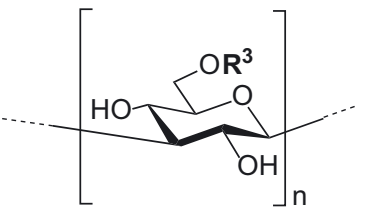

Mannitol

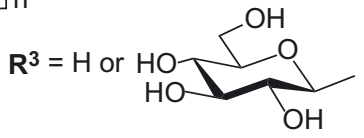

Fig. 1. The structures of the kelp constituent carbon sources used for enrichment cultivation of bacteria in the present study. The letters ' $\mathrm{n}$ ' and ' $\mathrm{m}$ ' indicate repeating units in the polymeric substances

Enrichment cultivation. The biofilm suspensions from the 6 kelp individuals were plated on the 6 different media described in the previous section in 3 different dilutions, corresponding to 5, 10 and $20 \mu \mathrm{l}$ per plate. Plates were incubated at $15^{\circ} \mathrm{C}$ in darkness for $4 \mathrm{wk}$. Colony counts were recorded for all plates and the sums of the counts of the 3 different dilutions per biofilm suspension and media type were used in further calculations. The colony diameter was measured for 30 randomly selected colonies on each plate and the average colony diameter of the 3 different dilutions per biofilm suspension and media type was calculated. Sixteen randomly selected colonies from each biofilm suspension and medium type were picked for colony PCR and sequencing.

Colony PCR and sequencing. Colony material was transferred with sterile pipette tips to $50 \mu \mathrm{l}$ PCR grade water in individual wells of a 96 well PCR microtiter plate. The colony suspensions were incubated at $99.9^{\circ} \mathrm{C}$ in a PCR thermocycler for $10 \mathrm{~min}$ to disrupt the cells and inactivate nucleases. The colony suspensions were immediately frozen and stored at $-20^{\circ} \mathrm{C}$ until further analyses. PCR amplification of a part of the $16 \mathrm{~S}$ rRNA gene of bacteria was carried out according to the PCR conditions described in Bengtsson et al. 2010, using $1 \mu$ of the colony suspensions as template for 25 $\mu l$ PCR reactions. The primers 1070 f $\left(5^{\prime}\right.$-ATG GCT GTC GTC AGC T-3') (Ferris et al. 1996) and 1392r (5' ACG GGC GGT GTG TRC-3') (Lane et al. 1985) that were used cover approximately $300 \mathrm{bp}$ of the $16 \mathrm{~S}$ rRNA gene. Positive PCR products were sequenced in
1 direction using the 1070 primer and BigDye Terminator v3.1 technology on an ABI 3700 sequencer (Applied Biosystems) at the Bergen sequencing facility (www.seqlab.uib.no).

Sequence analysis. Base calling of sequence chromatogram files was done using Phred (Ewing et al. 1998) and quality filtering and sequence end trimming was carried out via the Greengenes online interface (DeSantis et al. 2006). The quality-trimmed sequences were aligned against the Silva seed alignment, version 102 (Pruesse et al. 2007). The resulting alignment was imported into the software package ARB (version 5.0) (Ludwig et al. 2004) together with the 40 nearest neighbour reference sequences to each colony sequence. The alignment was manually edited in ARB to improve alignment quality. A distance matrix was constructed in ARB, using all alignment positions and Jukes-Cantor correction. The distance matrix was used to generate operational taxonomic units (OTUs) of different similarity thresholds in mothur (version 1.8.0) (Schloss et al. 2009), using the furthest neighbour clustering algorithm.

The sequences obtained from the enrichment cultivation experiment described in the present study were compared with sequences from indigenous kelp-associated bacterial communities obtained with cultivation-independent methods. These sequences comprised 587 bands obtained with denaturing gradient gel electrophoresis (DGGE) from bacterial communities collected during a seasonal cycle from kelp biofilms, the surrounding seawater and biofilms from the surfaces of the red seaweed Palmaria palmata that is an epiphyte on kelp. A 
part of this dataset, representing bands from Laminaria hyperborea meristem and lamina and seawater from 4 seasons, has been published in Bengtsson et al. (2010). The DGGE sequences were generated in that study using the same primers as described in 'Colony PCR and sequencing'. Sample collection and DGGE procedures are described in Bengtsson et al. (2010). All sequence analyses in the present study, including distance matrix construction and OTU clustering were carried out concomitantly using sequences from both the enrichment cultivation and cultivation-independent (DGGE) sources. One representative sequence (the longest) of each OTU (97\% similarity threshold) from the cultivation experiment have been deposited in GenBank under accession numbers HQ331511 to HQ331524.

Phylogenetic tree reconstruction. Full-length nearest neighbour 16S rRNA gene reference sequences obtained from the Silva 102 database (as described in the previous section) were used for tree calculations. Tree topologies were compared between Neighbour Joining and Maximum Likelihood (ML) tree calculation methods to ensure stable branching. The final ML tree was calculated with 601 full-length sequences in ARB using all alignment positions and an archaeal sequence (GenBank accession no. CP000866) as an outgroup. The partial sequences obtained in the present study were added to the tree afterwards, using the ARB parsimony tool. The tree was edited by removing all but one representative sequence of each OTU and all but the most closely related reference sequences.

Statistical analysis. Fishers exact test for count data (Fisher 1935) was used to test for independence of counts of 'growth' and 'no growth' of colonies of individual culturing media and individual OTUs. The significance of the test result was used to indicate whether or not the different culturing media influenced the OTU composition of the sequenced bacterial colonies. The statistical analyses were carried out in the R software for statistical computing (R Core Development Team 2010).

\section{RESULTS}

\section{Colony number and size}

The total numbers of colonies recorded on the different cultivation media are displayed in Fig. 2. The colony numbers give a range of 15 to 10485 colony forming units (CFUs) per $\mathrm{cm}^{2}$ of kelp surface if the sampled surface area that the inoculum volume represents is taken into account. Assuming that $1 \mathrm{CFU}$ corresponds to 1 bacterial cell, this equates to a cultivation success in the range of 0.0002 to $0.063 \%$, based on the counts of DAPI stained biofilm cells. The addition of kelp substances as carbon sources to the growth media

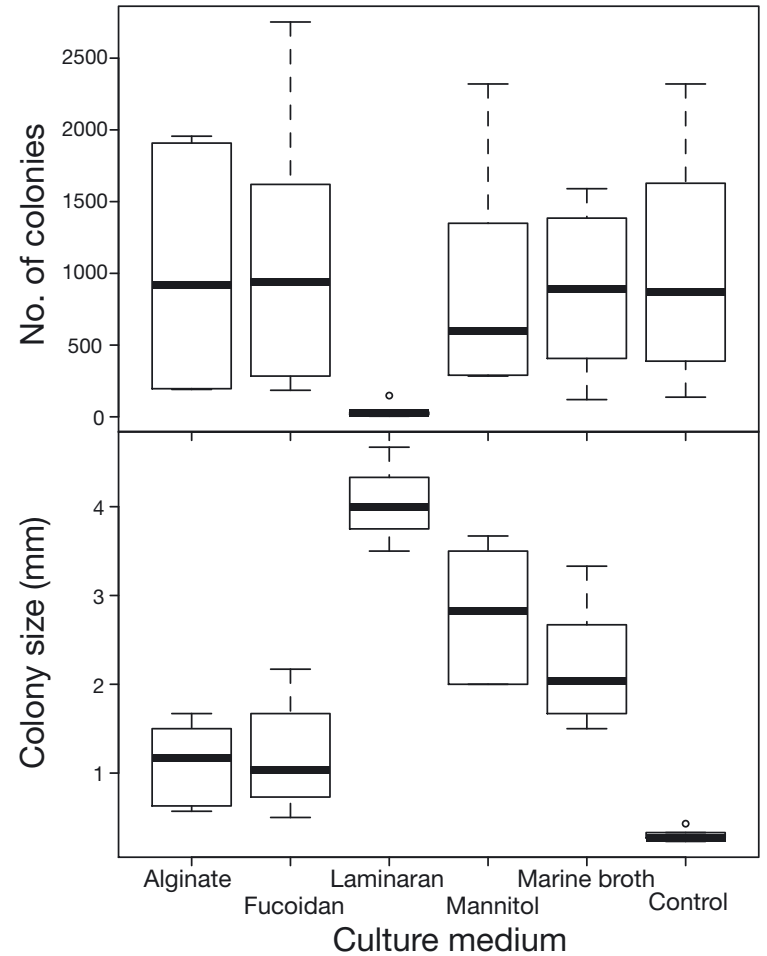

Fig. 2. Box plots illustrating the number of colonies (sum of 3 inoculum dilutions) and their average size (diameter) recorded for the different culture media. Diagrams depict the lower and upper quartiles (boxes), minimum and maximum (bars) and median (solid line) values of 6 different kelp individuals. Outliers ( ${ }^{\circ}$ ) are also shown

did not (with the exception of laminaran) result in any detectable difference in the number of bacterial colonies observed compared to the control medium that contained no kelp carbon source (Fig. 2). However, there was a clear increase in colony size in all kelpcarbon-source media compared to the control (Fig. 2). The bacterial colonies that grew on the control medium were all $<0.5 \mathrm{~mm}$ in diameter and barely visible to the naked eye. The larger colonies on all kelpcarbon-source media show that the addition of kelp substances indeed had an effect on bacterial growth, indicating that they are utilized as carbon sources by the bacteria. The most striking effect was observed for the medium containing laminaran, where a dramatic increase in colony size was accompanied by a decrease in colony number compared to the control medium and the other media (Fig. 2).

\section{Influence of culture media on bacterial OTU composition}

In total, 19 different OTUs at $97 \%$ sequence similarity were detected among the 282 colonies that were 
Table 1. Number of sequenced colonies belonging to each operational taxonomic unit (OTU) in the different culturing media. The actual number of colonies is given and the table cells are shaded according to the percentage of the total number of sequenced colonies for each medium. Significant $p$-values $\left({ }^{*} p<0.05\right)$ derived from Fishers exact test indicate that the occurrence of an OTU is influenced by a medium (columns) and that a medium influences the composition of OTUs (rows). The number of samples in which the OTU was detected by denaturing gradient gel electrophoresis (DGGE) in natural kelp surface biofilms is given. Cultured OTUs that occurred only once in the dataset are not displayed

\begin{tabular}{|c|c|c|c|c|c|c|c|c|}
\hline \multirow{2}{*}{$\begin{array}{l}\text { OTU } \\
\text { Medium }\end{array}$} & \multicolumn{4}{|c|}{ Carbon source type added to minimal base medium } & \multirow{2}{*}{$\begin{array}{l}\text { Complex } \\
\text { (Marine broth) }\end{array}$} & \multirow{2}{*}{$\begin{array}{c}\text { No } \\
\text { (Control) }\end{array}$} & \multirow[t]{2}{*}{ p-value } & \multirow{2}{*}{$\begin{array}{c}\text { Detection by } \\
\text { DGGE } \\
\text { (\# of samples) }\end{array}$} \\
\hline & Alginate & Fucoidan & Laminaran & Mannitol & & & & \\
\hline A1 & 4 & 3 & 0 & 4 & 4 & 3 & 0.89 & - \\
\hline A2 & 6 & 12 & 17 & 10 & 6 & 9 & $<0.001^{*}$ & - \\
\hline A3 & 22 & 22 & 2 & 29 & 26 & 20 & $0.006^{*}$ & 9 \\
\hline A4 & 2 & 6 & 0 & 1 & 0 & 4 & $0.04^{*}$ & - \\
\hline A5 & 0 & 3 & 0 & 3 & 0 & 0 & 0.08 & - \\
\hline A6 & 9 & 1 & 0 & 1 & 0 & 4 & $<0.001^{*}$ & - \\
\hline A7 & 0 & 0 & 2 & 1 & 2 & 1 & 0.09 & - \\
\hline A8 & 0 & 0 & 0 & 4 & 0 & 0 & $0.01^{*}$ & - \\
\hline A9 & 1 & 1 & 0 & 0 & 0 & 3 & 0.19 & - \\
\hline A10 & 4 & 0 & 1 & 1 & 5 & 1 & 0.07 & - \\
\hline A11 & 1 & 0 & 0 & 0 & 3 & 0 & 0.07 & 1 \\
\hline G1 & 3 & 0 & 0 & 0 & 0 & 0 & $0.05^{*}$ & 3 \\
\hline G2 & 0 & 0 & 0 & 1 & 1 & 0 & 0.08 & 6 \\
\hline F1 & 0 & 4 & 0 & 0 & 0 & 0 & $0.008^{*}$ & - \\
\hline p-value & $0.001^{*}$ & $0.004^{*}$ & $<0.001^{*}$ & $0.02^{*}$ & $0.005^{*}$ & 0.5 & & \\
\hline \multicolumn{9}{|c|}{ Percent of total in medium } \\
\hline & & $>60 \%$ & $40-60 \% 20-$ & $\% 10-20 \%$ & $5-10 \%<5 \%$ & & & \\
\hline
\end{tabular}

sequenced. The OTUs occurring only once were not included in the following analyses to reduce the influence of stochastic variation. The occurrence of the remaining 14 OTUs on the different cultivation media is displayed in Table 1. All media except the control had a significant influence on the bacterial OTU composition, and several of the OTUs were significantly influenced by the medium type according to the statistical analyses (using Fisher's exact test on individual growth media and OTUs). The OTUs that show a significant $(p<0.05)$ preference for one or more of the different culture media are indicated by an asterisk beside the $\mathrm{p}$-values in Table 1 . The overall OTU composition was dominated by 2 OTUs, A2 and A3, that were present on all culturing media, including the control (Table 1). Both of these OTUs were significantly influenced by medium type, and closer inspection revealed that A2 was overrepresented, while A3 was underrepresented on the laminaran medium. This indicates that A2 preferably utilizes laminaran while A3 shows no such preference. Both A2 and A3 appeared to be evenly represented on the other medium types. Of the less abundant OTUs, A8 was exclusively detected on the mannitol medium, G1 on the alginate medium and F1 on the fucoidan medium (Table 1). This may indicate that these OTUs are specialized in utilizing these substances. As all culturing media contained agar as a solidifying agent, some of the bacterial OTUs may be utilizing this as a carbon source. However, no depressions in the agar surface were observed associated with colonies, which is a common indication of agarolytic properties of bacteria. The OTUs that were also detected on the control medium, that contained no added carbon source, must be able to utilize agar or other trace carbon sources present in the medium or in the inoculum.

\section{Phylogenetic identity of the cultured bacteria}

The bacterial OTUs detected in this study belonged to the major bacterial lineages Alphaproteobacteria, Gammaproteobacteria and Firmicutes. A phylogenetic tree illustrating the relation of the OTUs with their closest relatives is displayed in Fig. 3. The OTUs A1 to A5 clustered among cultured and uncultured representatives of the Roseobacter clade (Fig. 3), a relatively well-studied group within the Alphaproteobacteria. Remaining alphaproteobacterial OTUs (A9 to A11), cluster with other cultured strains, many of which contain bacteriochlorophyll and have a photoheterotropic lifestyle. The gammaproteobacterial OTU G1 has no close cultured relatives, and clusters with a cloned sequence from arctic marine sediment (Fig. 3), while G2 is related to Granulosicoccus antarcticus isolated from seawater (Lee et al. 2007). One OTU (F1) belonged to Firmicutes and clustered with a cultured Bacillus strain isolated from the sediment of an estuary. 


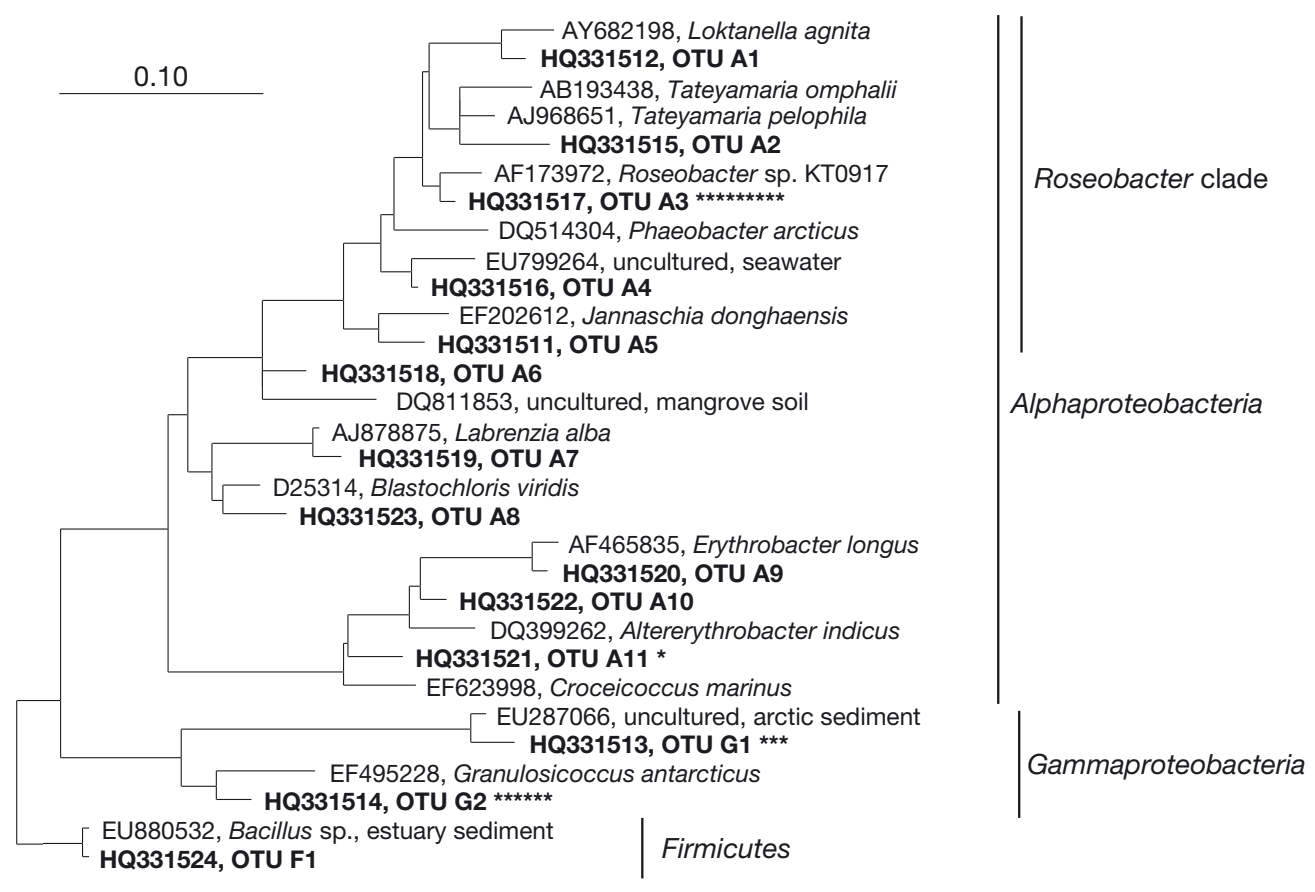

Fig. 3. A maximum likelihood tree of 16S rRNA gene sequences displaying the OTUs that were detected more than once in the enrichment cultivation experiment (in bold), as well as closely related reference sequences (represented by Genbank accession number and name/description). The number of asterisks beside OTU names indicate the number of samples that the OTU was detected in by cultivation-independent DGGE. The tree was calculated with 600 full length 16S rRNA gene sequences from bacteria and one archaeal outgroup sequence. All but the reference sequences that were the most closely related to the cultivation OTUs have been removed for clarity of presentation. The scale bar indicates $10 \%$ sequence divergence

\section{Similarity between cultivated bacteria and bacteria detected on indigenous kelp surface biofilms}

The OTU composition of the cultured bacteria differed substantially from that of natural kelp biofilms as revealed by comparison with sequences obtained with the cultivation-independent method DGGE, comprising 119 (97\% similarity cut-off). For example, 2 of the most frequently detected major bacterial lineages on natural kelp biofilms, Planctomycetes and Verrucomicrobia, were not detected among the cultured bacteria in this study. However, several of the cultured OTUs (97\% similarity cut-off) were also detected in kelp surface biofilms (marked with asterisks in Fig. 3). As DGGE has a limited sensitivity, it can only detect relatively abundant members of a community. Therefore, the detection of cultured OTUs by DGGE on kelp surfaces indicates that identical or closely related bacterial species indeed reach high abundances also under natural conditions. The most abundant cultured OTU, A3, was detected by DGGE on kelp surfaces in February, May, September and November (in a total of 9 samples) as well as on the surface of the red alga Palmaria palmata in September (in 1 sample) and in seawater in May (in 2 samples). The OTU A11 was detected on kelp surfaces in July (in 1 sample). Both gammaproteobacterial OTUs were detected on natural kelp surfaces, G1 in February, May and July (in 1 sample in each season) and G2 in February (in 1 sample), March (in 3 samples) and May (in 2 samples).

\section{DISCUSSION}

The kelp surface is a habitat rich in potential carbon sources for heterotrophic bacteria. The kelp fixes carbon through photosynthesis. Some of this carbon is exudated from the cells (Abdullah \& Fredriksen 2004) and some is stored inside the cells, primarily in the form of mannitol and laminaran. The stored carbon is mobilized when it is used for biosynthesis of new kelp tissue, which to a large extent consists of alginate originating from brown seaweed cell wall material (Haug \& Jensen 1954). The kelp also excretes mucus on its surface, which in part consists of the sulfated polysaccharide fucoidan (Evans et al. 1973). Knowledge of how these carbon sources are utilized by bacteria is essential for understanding the flux of carbon in kelp forest ecosystems. In the present study, enrichment cultivation of bacteria from kelp surfaces using kelp 
constituent carbon sources was used to identify bacteria able to degrade these kelp-derived substances. The results highlight a few bacterial OTUs that may be important in these processes, some of which are also detected in high abundances in indigenous kelp biofilms.

It must be pointed out that bacteria belonging to the same OTU at $97 \%$ partial 16S rRNA gene sequence similarity are not necessarily derived from the same bacterial species sharing the same phenotypic traits and ecological roles as even strains showing 100\% 16S rRNA gene similarity can vary considerably in their phenotypic features (see Hanage et al. 2006 and references therein). However, we consider the clustering of sequences into OTUs a useful tool to study trends in community composition as a first step towards linking community structure to function. More detailed physiological analyses are required to definitively link phylogenetic identity to function and are beyond the scope of the present study.

The majority of the OTUs that were captured by cultivation in the present study belong to the Roseobacter clade of Alphaproteobacteria (Fig 3). Roseobacters are frequently recovered by cultivation-based and cultivation-independent methods in a wide variety of marine habitats and are often dominant community members (Buchan et al. 2005). Several genome sequences of roseobacters already exist, and genomic and physiological data describe a bacterial lineage with considerable metabolic versatility (Newton et al. 2010). The most abundant OTU detected in the present study, A3, clusters within the Roseobacter clade (Fig. 3) and is closely related to a strain isolated from the North Sea (Eilers et al. 2000). A3 was able to grow on all of the culturing media tested in the present study (Table 1), which suggests that it is a generalist that can utilize many different carbon sources. The detection of A3 on kelp surfaces in different seasons, on the surfaces of a red alga as well as in seawater further supports the notion of a generalist lifestyle. Its ability to reach high abundances - both in culture and occasionally under natural conditions - suggests that A3 is an opportunist, combining a wide substrate affinity with a fast growth rate in order to reach high abundances when the conditions are temporarily suitable. The roseobacterial OTU A2, was also detected on all culturing media (Table 1). However, A2 was clearly overrepresented on the medium containing laminaran (Table 1), indicating that it has a special affinity for this carbon source. The few but on average large colonies that were observed on the laminaran medium (Fig. 2) consisted of bacteria of this OTU. A2 is closely related to bacterial strains of the newly described genus Tateyamaria (Fig. 3). T. pelophila, that was isolated from tidal flat sediments (Sass et al. 2010), like A2 has the ability to utilize laminaran, while T. omphalii (Kurahashi \&
Yokota 2007), isolated from the shell of a mollusc, does not (Sass et al. 2010). Both described strains are otherwise versatile in their carbon source utilization, as A2 also appears to be. A2 was not detected with DGGE in indigenous kelp surface biofilms, indicating that it is a relatively low abundance community member.

Both of the 2 gammaproteobacterial OTUs, G1 and G2, were also detected in indigenous kelp surface biofilms. G1 may be an alginate degrader on kelp surfaces based on its preference for the culture medium containing alginate (Table 1). G2 is closely related to the bacterial strain Granulosicoccus antarcticus isolated from seawater close to Antarctica (Lee et al. 2007). It was detected on kelp surfaces predominantly in March and May, when the kelp surface tissue is growing rapidly, which may indicate that it is one of the early colonizers of newly formed kelp surfaces.

As in virtually all cultivation efforts of environmental bacteria, the bacteria that were captured by cultivation in the present study were not the same as those which dominate kelp surface biofilm communities under natural conditions. The most frequently detected OTUs in kelp surface biofilms belong to Planctomycetes, Alphaproteobacteria and Verrucomicrobia (Bengtsson et al. 2010) and were not detected by cultivation in the present study. The maximum culturability of $0.06 \%$ of kelp biofilm cells in this experiment makes the cultured OTUs relatively rare community members on the kelp surfaces that were sampled. However, the detection of some of the same OTUs by cultivation-independent methods in other samples indicates that these organisms (or close relatives) do occasionally reach high abundances also under natural conditions. This confirms that these OTUs are not random guests on the kelp surfaces, but can play an important role when conditions allow them to multiply.

Culture media containing kelp constituent carbon sources represent an environment that is distinctly different from living kelp surfaces in many ways. One factor that is likely to influence kelp surface biofilm communities strongly, but not laboratory cultures, is biotic interactions between different bacteria and, importantly, between the kelp itself and the bacteria. While the kelp is alive and healthy, not all of its carbon sources are available for microbial utilization, due to microbial defense strategies of the kelp. These strategies are not well understood (Goecke et al. 2010), but there are indications that the kelp can select for a nondestructive microbial community on its surface. For example, the kelp Laminaria digitata reacts with an oxidative burst, exudating hydrogen peroxide that can kill attached bacteria when it is exposed to oligoguluronates - building blocks of alginate that can be released during bacterial breakdown of kelp cell walls (Küpper et al. 2001). The composition of kelp surface 
bacterial communities on living kelp surfaces is therefore likely to reflect such defense strategies, and a predominance of bacteria that do not harm the kelp by degrading structural or intracellular kelp constituents such as alginate and laminaran may be expected. Instead, the most abundant kelp surface bacteria may utilize dissolved carbon that is exudated from kelp cells as well as fucoidan or other components of the extracellular mucus found on kelp surfaces. An example of this strategy may be found within the Planctomycetes lineage, which often dominates the indigenous communities on kelp surface biofilms (Bengtsson \& Øvreås 2010). Some marine Planctomycetes are hypothesized to be specialized degraders of sulphated polysaccharides (Woebken et al. 2007), such as fucoidan, which might enable them to utilize kelpproduced carbon without harming the kelp and thereby eliciting microbial defense responses. Culture media containing kelp constituent carbon sources are devoid of kelp microbial defenses and may rather resemble dead kelp material, where all constituents of the kelp cells are available for microbial degradation. Thus, the bacterial OTUs detected with this enrichment cultivation approach, may be more important in degradation of dead kelp material than utilization of the exudates and excretions of living kelp cells. For example, the combination of a wide carbon source affinity with a fast growth rate, such as displayed by the Roseobacter OTUs, A2 and A3, would make them successful opportunists, taking advantage of the rich carbon sources present in kelp material that become available upon the death of kelp cells.

\section{CONCLUSIONS}

The most abundant bacteria captured by the enrichment cultivation approach using kelp constituent carbon sources belonged to the Roseobacter clade of Alphaproteobacteria. Other Alphaproteobacteria and Gammaproteobacteria were also among the cultured bacteria. Several of the cultured OTUs also occasionally reached high abundances in natural kelp surface biofilms at different times of the year. The sporadic nature of their detection on kelp surfaces and their apparent generalist lifestyles suggests that they are opportunists that may be important in degradation of dead kelp material. The present study provides a fresh look on the culturable fraction of bacteria associated with kelp, and links their identity to possible ecological roles in the environment. This bridges the gap between cultivation-based approaches that have been traditionally used to study kelp-associated bacteria and the cultivation-independent methods that are the cornerstones of microbial ecology research today.
Acknowledgements. The authors thank Tomas Sørlie for assistance during sampling, Knut Helge Jensen for advice on statistics, Thomas Norberg for providing the chemical structures in Fig. 1 and FMC Biopolymer for providing the kelp constituents used in the cultivation experiments as well as funding for the study. Additional funding was provided through a scholarship awarded to M.M.B. from Egil and Sunniva Baardseths Legat. Two anonymous reviewers made constructive and encouraging comments on the manuscript.

\section{LITERATURE CITED}

Abdullah M, Fredriksen S (2004) Production, respiration and exudation of dissolved organic matter by the kelp Laminaria hyperborea along the west coast of Norway. J Mar Biol Assoc UK 84:887-894

> Bengtsson MM, Øvreås L (2010) Planctomycetes dominate biofilms on surfaces of the kelp Laminaria hyperborea. BMC Microbiol 10:261 doi:10.1186/1471-2180-10-261

Bengtsson MM, Sjøtun K, Øvreås L (2010) Seasonal dynamics of bacterial biofilms on the kelp Laminaria hyperborea. Aquat Microb Ecol 60:71-83

Black WAP (1954) The seasonal variation in the combined L-fucose content of the common British Laminariaceae and Fucaceae. J Sci Food Agric 5:445-448

> Buchan A, Gonzalez J, Moran M (2005) Overview of the marine Roseobacter lineage. Appl Environ Microbiol 71: 5665-5677

Chesters C, Bull A (1963) Enzymic degradation of laminarin. 1. Distribution of laminarase among micro-organisms. Biochem J 86:28-31

> Christie H, Jorgensen N, Norderhaug K, Waage-Nielsen E (2003) Species distribution and habitat exploitation of fauna associated with kelp (Laminaria hyperborea) along the Norwegian coast. J Mar Biol Assoc UK 83:687-699

> Davis CL, Koop K, Muir DG, Robb FT (1983) Bacterial diversity in adjacent kelp-dominated ecosystems. Mar Ecol Prog Ser 13:115-119

> DeSantis TZ, Hugenholtz P, Larsen N, Rojas M and others (2006) Greengenes, a chimera-checked 16S rRNA gene database and workbench compatible with ARB. Appl Environ Microbiol 72:5069-5072

> Descamps V, Colin S, Lahaye M, Jam M, and others (2006) Isolation and culture of a marine bacterium degrading the sulfated fucans from marine brown algae. Mar Biotechnol 8:27-39

> Eilers H, Pernthaler J, Glockner F, Amann R (2000) Culturability and in situ abundance of pelagic bacteria from the North Sea. Appl Environ Microbiol 66:3044-3051

Evans LV, Simpson M, Callow ME (1973) Sulphated polysaccharide synthesis in brown algae. Planta 110:237-252

Ewing B, Hillier L, Wendl M, Green P (1998) Base-calling of automated sequencer traces using phred. I. Accuracy assessment. Genome Res 8:175-185

Ferris MJ, Muyzer G, Ward DM (1996) Denaturing gradient gel electrophoresis profiles of $16 \mathrm{~S}$ rRNA-defined populations inhabiting a hot spring microbial mat community. Appl Environ Microbiol 62:340-346

Fisher RA (1935) The logic of inductive inference. J R Stat Soc 98:39-82

Goecke F, Labes A, Wiese J, Imhoff JF (2010) Chemical interactions between marine macroalgae and bacteria. Mar Ecol Prog Ser 409:267-300

Hanage WP, Fraser C, Spratt BG (2006) Sequences, sequence clusters and bacterial species. Philos Trans R Soc Lond B Biol Sci 361:1917-1927 
Haug A, Jensen A (1954) Seasonal variations in the chemical composition of Alaria esculenta, Laminaria saccharina, Laminaria hyperborea and Laminaria digitata from northern Norway. Rep Norwegian Inst Seaweed Res 4:1-14

Hollohan B, Dabinett P, Gow J (1986) Bacterial succession during biodegradation of the kelp Alaria esculenta (L.) Greville. Can J Microbiol 32:505-512

Koop K, Carter RA, Newell RC (1982) Mannitol-fermenting bacteria as evidence for export from kelp beds. Limnol Oceanogr 27:950-954

Küpper FC, Kloareg B, Guern J, Potin P (2001) Oligoguluronates elicit an oxidative burst in the brown algal kelp Laminaria digitata. Plant Physiol 125:278-291

Kurahashi M, Yokota A (2007) Tateyamaria omphalii gen. nov., sp. nov., an alpha-proteohacterium isolated from a top shell Omphalius pfeifferi pfeifferi. Syst Appl Microbiol 30:371-375

Lane DJ, Pace B, Olsen GJ, Stahl DA, Sogin ML, Pace NR (1985) Rapid determination of 16S ribosomal RNA sequences for phylogenetic analyses. Proc Natl Acad Sci USA 82:6955-6959

- Laycock RA (1974) The detrital food chain based on seaweeds. I. Bacteria associated with the surface of Laminaria fronds. Mar Biol 25:223-231

Lee K, Lee HK, Choi TH, Kim KM, Cho JC (2007) Granulosicoccaceae fam. nov., to include Granulosicoccus antarcticus gen. nov., sp. nov., a non-phototrophic, obligately aerobic chemoheterotroph in the order Chromatiales, isolated from Antarctic seawater. J Microbiol Biotechnol 17: 1483-1490

Ludwig W, Strunk O, Westram R, Richter L and others (2004) ARB: a software environment for sequence data. Nucleic Acids Res 32:1363-1371

Newell RC, Field JG (1983) The contribution of bacteria and detritus to carbon and nitrogen flow in a benthic community. Mar Biol Lett 4:23-36

Newton RJ, Griffin LE, Bowles KM, Meile C and others (2010) Genome characteristics of a generalist marine bacterial lineage. ISME J 4:784-798

Norderhaug K, Fredriksen S, Nygaard K (2003) Trophic importance of Laminaria hyperborea to kelp forest consumers and the importance of bacterial degradation to food quality. Mar Ecol Prog Ser 255:135-144

Pruesse E, Quast C, Knittel K, Fuchs BM, Ludwig W, Peplies J, Gloeckner FO (2007) SILVA: a comprehensive online resource for quality checked and aligned ribosomal RNA sequence data compatible with ARB. Nucleic Acids Res $35: 7188-7196$

Editorial responsibility: Staffan Kjelleberg,

Sydney, New South Wales, Australia
R Development Core Team (2010) R: A language and environment for statistical computing. R Foundation for Statistical Computing, Vienna, Austria. www.R-project.org

> Sakai T, Kimura H, Kato I (2002) A marine strain of Flavobacteriaceae utilizes brown seaweed fucoidan. Mar Biotechnol 4:399-405

- Sakai T, Ishizuka K, Kato I (2003) Isolation and characterization of a fucoidan-degrading marine bacterium. Mar Biotechnol 5:409-416

Sass H, Koepke B, Ruetters H, Feuerlein T, Droege S, Cypionka H, Engelen B (2010) Tateyamaria pelophila sp. nov., a facultatively anaerobic alphaproteobacterium isolated from tidal-flat sediment, and emended descriptions of the genus Tateyamaria and of Tateyamaria omphalii. Int J Syst Evol Microbiol 60:1770-1777

Schloss PD, Westcott SL, Ryabin T, Hall JR and others (2009) Introducing mothur: open-source, platform-independent, community-supported software for describing and comparing microbial communities. Appl Environ Microbiol 75: $7537-7541$

Staufenberger T, Thiel V, Wiese J, Imhoff JF (2008) Phylogenetic analysis of bacteria associated with Laminaria saccharina. FEMS Microbiol Ecol 64:65-77

Tokida J (1960) Marine algae epiphytic on Laminariales plants. Bull Fac Fish Hokkaido Univ 11:73-105

- Uchida M (1995) Enzyme activities of marine bacteria involved in Laminaria-thallus decomposition and the resulting sugar release. Mar Biol 123:639-644

> Wada S, Aoki MN, Tsuchiya Y, Sato T, Shinagawa H, Hama T (2007) Quantitative and qualitative analyses of dissolved organic matter released from Ecklonia cava Kjellman, in Oura bay, Shimoda, Izu Peninsula, Japan. J Exp Mar Biol Ecol 349:344-358

> Whitman WB, Bowen TL, Boone DR (2006) The methanogenic bacteria. Prokaryotes 3:165-207

> Woebken D, Teeling H, Wecker P, Dumitriu A and others (2007) Fosmids of novel marine Planctomycetes from the Namibian and Oregon coast upwelling systems and their cross-comparison with planctomycete genomes. ISME J 1:419-435

> Wolin EA, Wolin MJ, Wolfe RS (1963) Formation of methane by bacterial extracts. J Biol Chem 238:2882-2886

- Wong TY, Preston LA, Schiller NL (2000) Alginate lyase: review of major sources and enzyme characteristics, structure-function analysis, biological roles, and applications. Annu Rev Microbiol 54:289-340

Submitted: October 4, 2010; Accepted: November 24, 2010

Proofs received from author(s): January 4, 2011 